\title{
DECLARACIÓN DE MÁLAGA SOBRE LA BIODIVERSIDAD Y EL DESARROLLO SOSTENIBLE EN EL MEDITERRÁNEO NERSIÓN RESUMIDAI
}

\section{MED Forum}

(Red de ONGs del Mediterráneo para la Ecología y el Desarrollo Sostenible)

Durante las sesiones de la Conferencia Mediterránea: Espacios protegidos, conservación de la biodiversidad y desarrollo sostenible en el Mediterráneo. Lineas estratégicas y buenas prácticas, a la que han asistido 125 representantes de diferentes ONG, instituciones, académicos y expertos de la región mediterránea, se han debatido propuestas concretas sobre estrategias de protección de biodiversidad. A propuesta de los asistentes, y reunido el Consejo Mediterráneo de MED Forum, éste ha aprobado la siguiente

\section{DECLARACIÓN:}

Afirmamos que el Mediterráneo dispone de unas condiciones medioambientales que permiten la existencia de una rica diversidad biológica, tanto marina como terrestre, que se encuentra amenazada por la fuerte entropía que padece toda la cuenca mediterránea. Las fuertes presiones que recibe la estrecha franja litoral, que se extiende a lo largo de los más de 46.000 kilómetros de costa, ponen en peligro los frágiles ecosistemas existentes.

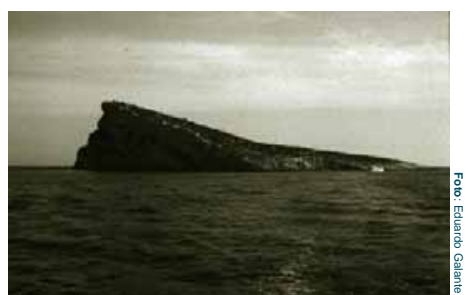

Imagen de la Isla de Benidorm (Alicante)
Queremos dejar constancia, que a pesar de la depredación de recursos naturales y la desaparición de ecosistemas de gran valor, aún existen grandes zonas que merecen un mayor grado de protección para conseguir su conservación y su compatibilidad con un desarrollo sostenible:

- Existen más de 10.000 especies marinas.

- Hay más de 25.000 especies vegetales (fanerógamas), de las que el $50 \%$ son endémicas.

- Hay 5.000 millones de aves migratorias pertenecientes a 150 especies de las 500 conocidas en la región.

- El bosque cubre tan sólo el 9,4\% del territorio.

- Existen un millón de hectáreas de zonas húmedas que constituyen las mejores zonas de descanso de las migraciones de aves.

- Especialmente preocupantes son las amenazas sobre los sistemas.

- De 145 razas bovinas, 115 se consideran en vías de extinción y de 49 razas de cabras, 33 están también amenazadas.

- Poco más del 1\% de la zona litoral mediterránea goza de alguna protección.

\section{Ante todo ello, PROPONEMOS:}

1. Promover la gestión integrada y sostenible de todo el litoral mediterráneo, estableciendo, entre otras cosas, la limitación de la urbanización de las zonas costeras y declarando un mínimo del 20\% de litoral marítimo terrestre con figuras de protección estricta. 
2. Instar a la creación de un Fondo para la Protección del Litoral mediterráneo, destinado a la adquisición de zonas de gran valor ecológico, cultural y paisajístico, con fines de conservación, protección, educación, información y uso social sostenible.

3. Poner en marcha medidas para la protección y conservación de ecosistemas, hábitats y especies amenazados, tanto en los espacios protegidos como en los adyacentes, derivados del desarrollo urbano y de infraestructuras, de prácticas agrícolas, del uso indiscriminado y excesivo de áreas comunales para fines de explotación ganadera, de actividades turísticas y de la contaminación.

4. Evitar que los espacios naturales sean islas en un océano de espacios perturbados, artificializados o degradados. Establecer normas que impidan la fragmentación y aislamiento de los espacios, como son las vallas de cotos de caza, sistemas viales y otras obras de infraestructuras y parcelamiento. Crear redes de espacios naturales tanto a escala nacional, como regional e internacional. Recurrir a los corredores ecológicos o de conservación que vinculen las áreas protegidas entre ellas.

5. Implementar políticas de desarrollo sostenible que reconcilien la dimensión social, económica, política, cultural y ecológica. Integrar las poblaciones de los asentamientos humanos incluidos en el perímetro de los espacios protegidos así como aquellos directamente vinculados a ellos en la gestión, conservación y uso sostenible del espacio protegido.

6. Fortalecer los mecanismos de participación de la sociedad civil. Es de especial importancia que las ONGs del Mediterráneo asuman responsabilidades en las labores de educación, formación y gestión concernientes a la protección de los espacios

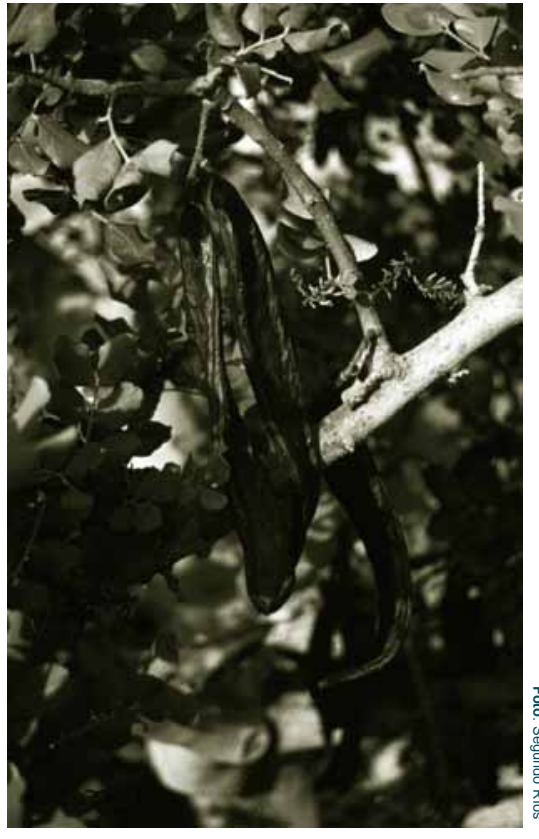

naturales y la conservación biológica.

7. Adoptar las medidas que impidan la reducción de las zonas húmedas habida cuenta de la importancia de sus funciones reguladoras, de protección, productivas, de información y de apoyo a actividades económicas, así como por su riqueza biológica y en particular su papel como hábitat y espacio de cría de las especies migratorias.

8. Realizar una planificación y gestión integrada y sostenible del sistema insular Mediterráneo para preservar sus ricos y frágiles valores naturales y culturales. Dicha planificación y gestión debe realizarse de forma participativa asociando a las poblaciones locales y a las ONGs. Debe regularse la presión humana para evitar que una excesiva presencia amenace el patrimonio natural y cultural insular.

9. Reconocer el valor de las tierras agrícolas para la conservación de la diversidad biológica e integrarlas explícitamente en las estrategias de conservación y uso sostenible de la diversidad biológica. Habrá que considerar entre otras cosas el papel de los microorganismos y en general la microfauna de los suelos, desarrollando técnicas e instrumentos para la integración rutinaria de los valores de la diversidad biológica en la gestión y los usos del suelo, la gestión de los setos, cercos, espacios de arbustos, bancales y terrazas y riberas.

10. Establecer regulaciones para la preservación de los hábitats y las comunidades marinas. Determinar la capacidad de respuesta de las comunidades acuáticas a la explotación pesquera. Determinar los niveles óptimos de captura compatible con la preservación del máximo de biodiversidad, garantizando que las especies más vulnerables no sean sobre-explotadas y se reduzca la pesca incidental o fauna de acompañamiento. Buscar alternativas viables a las 


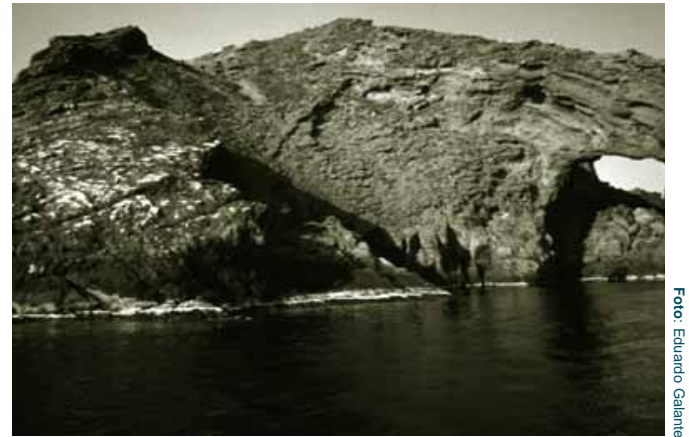

Imagen de la Isla Foradada, en el archipiélago de las Columbretes (Castellón)

artes de pesca altamente destructoras como las redes de deriva y de arrastre de fondo.

11. Regular las actividades de caza y de recolección de especies y variedades silvestres y adoptar las medidas adecuadas tanto para asegurar su propia preservación como garantizar el mantenimiento de las funciones que desempeñan.

12. Regular y controlar la introducción deliberada y accidental de especies foráneas y genéticamente modificadas por sus efectos sobre la diversidad biológica y sobre la actividad agronómica.

13. Proteger con medidas concretas el rico y diverso patrimonio cultural y monumental mediterráneo y sus entornos naturales como un valor fundamental de diversidad.

14. Promover el establecimiento de normas, en el ámbito mediterráneo y en cada país, que exijan necesariamente la evaluación del impacto de todo desarrollo urbanístico, de las infraestructuras, del turismo y, en general, de las actividades económicas. La norma deberá incluir además mecanismos de vigilancia y sugerir normas de gestión ambiental adecuadas en las actividades mencionadas.

Pedimos a los países mediterráneos que asuman las obligaciones derivadas de la ratificación del Convenio sobre diversidad biológica e implementen las medidas requeridas.

Debería avanzarse en la articulación de los diferentes Convenios internacionales que afectan al Mediterráneo a través de la coordinación a realizar por el Plan de Acción del Mediterráneo (PAM-PNUMA).

MED Forum ha aprobado esta Declaración, que fue ampliamente debatida durante la Conferencia
Mediterránea y posteriormente en el Consejo Mediterráneo, y se compromete a llevar a cabo las siguientes tareas:

- Difundir los contenidos de esta Declaración y buscar los apoyos necesarios para conseguir su aplicación.

- Elaborar un Libro-guía de buenas prácticas con relación a espacios protegidos, conservación de la biodiversidad y desarrollo sostenible en el Mediterráneo, en base a los proyectos presentados durante la Conferencia Mediterránea.

- Buscar la potencial reproducción de nuestros proyectos locales mediante el mantenimiento de una perspectiva regional (mediterránea) en nuestro trabajo diario.

- Aprovechar los contactos realizados durante este taller para preparar proyectos regionales y buscar fondos para la ejecución de nuevos proyectos, en régimen de partenariado en el seno de MED Forum, basados en estas experiencias (SMAP, METAP, etc.).

Málaga (España), 22 de noviembre de 1999

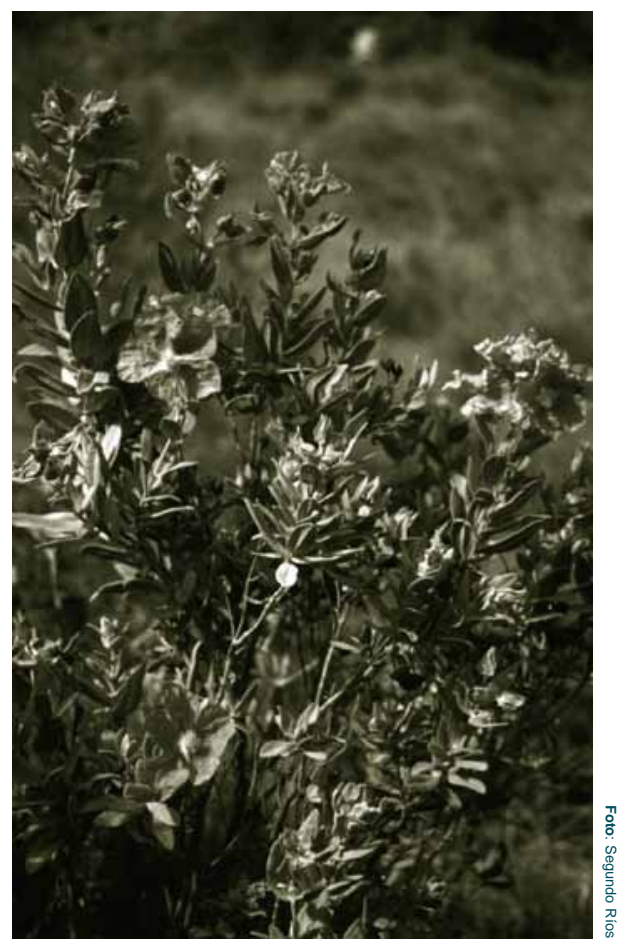

Una planta típicamente mediterránea, Cistus albidus $L$. 